\title{
Retreatment of a Failed Quad Zygoma Implant Procedure with Cortically Fixed at once Hybrid Plates: Case Report
}

\author{
Jimoh Olubanwo Agbaje ${ }^{1 *}$, Marc Pifarre Portella ${ }^{2}$ and Henri Diederich ${ }^{3}$ \\ ${ }^{1}$ Department of Imaging and Pathology, Faculty of Medicine, Catholic University Leuven, Belgium \\ ${ }^{2}$ Clinica Dental Pifarre, Barcelona, Spain \\ ${ }^{3}$ Dental Clinic Henri Diederich, Luxembourg
}

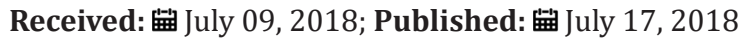

*Corresponding author: Henri Diederich, Dental surgeon, Dental Clinic Henri Diederich, Luxembourg

\begin{abstract}
Retreatment of previous failed implant surgeries with zygoma implants. The zygoma implant failed due to a possible overload and lack of osseointegration of the implants. This is further complicated by the existing problem of edentulism. Further loss of bone height associated with loss implant and the presence of scar tissue in the previous operated and implant site make reoperation difficult. This article describes a clinical procedure for the restoration of severely resorbed maxilla after a failed standard and zygomatic implants with Cortically Fixed at Once (CF@0) implant system. Rehabilitation of difficult and failed implant case is achieved within a short period of time without the need for extensive surgical operation. Early loading ensures that patient edentulism can be taken care of immediately.
\end{abstract}

Keywords: Cortically Fixed at Once Approach Implants; Failed Implants; Hybrid Plates; Edentulous Patient; Rehabilitation

\section{Introduction}

Restoration of a severely edentulous arch poses an enormous challenge to the dentist more so in the maxillary region where various anatomical structures reduce the option for extensive surgery. Bone augmentation may be required to enable placement of a sufficient number and length of implants to support an implant prosthesis [1,2]. Retreatment of failed implant further complicates the existing problem because of further loss of bone height associated with loss implant and the presence of scar tissue in the previous operated and implant site which make reoperation difficult. Zygomatic Implants have been used to provide support for oral rehabilitation where there has been a substantial amount of bone loss from the upper jaw due to resorption or implant failure $[3,4]$.

Ridge augmentation, on lay and placement of long implants such as zygomatic or pterygoid implants are documented means of rehabilitating a severely resorbed ridge and that with good success [2,5-8]. However, when any of these methods of rehabilitation fails, the option left for the restoration of an atrophic arch for patient and dentist is very limited. Extensive surgeries are usually not recommended because of lack of wiliness on the part of the patient to go through such an extensive surgery, and also because of the reduced chance of success of such surgical procedures $[9,10]$. The resorption of free bone graft during healing make it a poor candidate for rehabilitation especially after implant failure [11].
In some cases, the patient has to make do with a removable prosthesis which in the maxilla is poorly retained due to loss of bone height and extensive resorption of the alveolar ridge. This often leaves patient and dentist in a state of despair since in most cases an option of good rehabilitation after successively failed implants is very limited. Here we presented a case of the rehabilitation of a severely resorbed ridge (after successive failed of standard and zygomatic implants rehabilitation) with CFAO hybrid plates.

\section{Case Presentations}

The patient is a 68-year-old female with a previous history of several failed implant in the past 30 years, due to the previous history of several failed implant and severe resorption of the maxillary ridge, quad zygoma implant was placed for the rehabilitation of the upper edentulous arch three years ago with immediate loading. The zygoma implant in position 26 was lost 6 months after placement, the lost Zygoma implant was removed and replaced with a Pterygoid implant and the prosthesis was redone. Recently, the patient presented at the clinic with a complaint of movement of the upper prosthesis. A clinical examination showed a fractured upper prosthesis and edentulous upper arch with a severely resorbed ridge, and a mobile zygoma on position 13 and 15, there was a pain on percussion with a slight rotational movement of the zygoma on palpation. Radiographic examination using an orthopantomogram showed an upper jaw with vertical bone resorption and fracture of the pterygoid implant (Figure 1). 


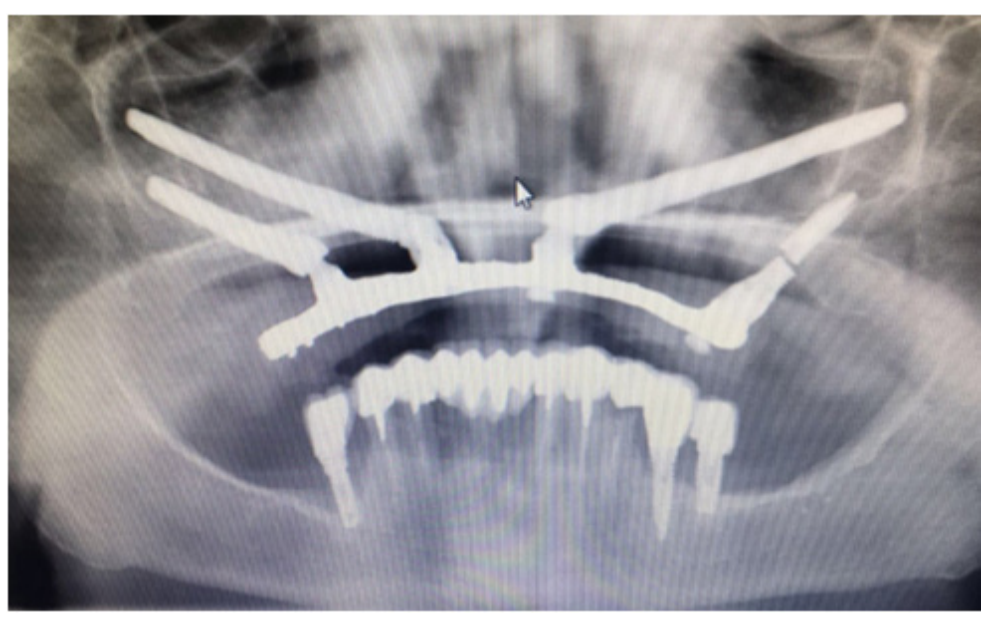

Figure 1: Panoramic radiograph of the patient at presentation showing edentulous upper arch with failed zygomatic implant and fracture of the pterygoid implant.

\section{Treatment Plan}

In the upper jaw, the treatment options are the removal of two failed zygoma implants and the broken pterygoid implant. Patient prefers an immediate treatment option. The proposed plan was the placement of a combination of two pterygoid and three hybrid plates after the after removal of the fractured and failed implants. The patient agreed to this treatment plan. In the maxilla, the failed zygoma implants were removed and an open flap was made from the left tuberosity along the crest till the canine region. The flap was reflected on the vestibular side in positions 26 and 27 of the zygomatic arch; flap was also reflected in the palate. Pterygoid implant P3.5/20 mm was inserted at the left pterygoid plate. A plate HENGG-1(Highly efficient no graft gear) was installed in position 26. The zygoma implant on the left (position 22) was in good condition, however, it was reinforced with titanium vestibular plate (Figure 2).
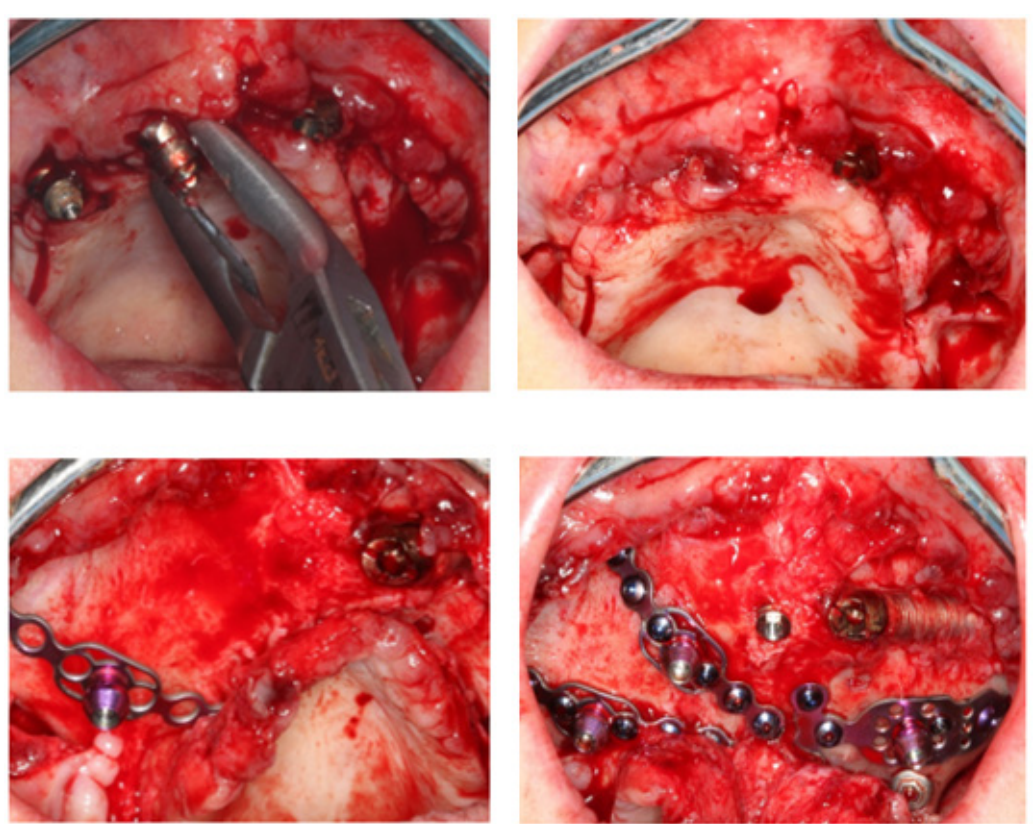

Figure 2: Surgical procedure, failed zgoma implant removal (a) and implant placement in the maxilla (b,c and d).

The plates were fixed with osteosynthesis screws and covered with MatriboneR. The procedure was quite similar for the right side. Pterygoid implant P3.5/20mm was inserted at the right pterygoid plate. Two hybrid plates HENGG-2 were fixed at positions 13 and 16. A Nasopalatine implant ( $8 \mathrm{~mm}$ length and 4.5 width) was also placed to reinforce the procedure (Figure 3). The flap was then closed on the left and right with polytetrafluoroethylene polymer (PTFE) monofilament non-absorbable suture. After an implant placement, the first bite registration was done with the old prosthesis of the patient. Then transfer coping was inserted and an impression was taken with silicone. Immediate loading was done with $2 \mathrm{~mm}$ bar. At the following appointment, the upper prosthesis was delivered. The patient was reviewed after 2 weeks. Thereafter, the patient was scheduled for follow-up at 3 months and then every 6 months (Figures 4 \& 5). 


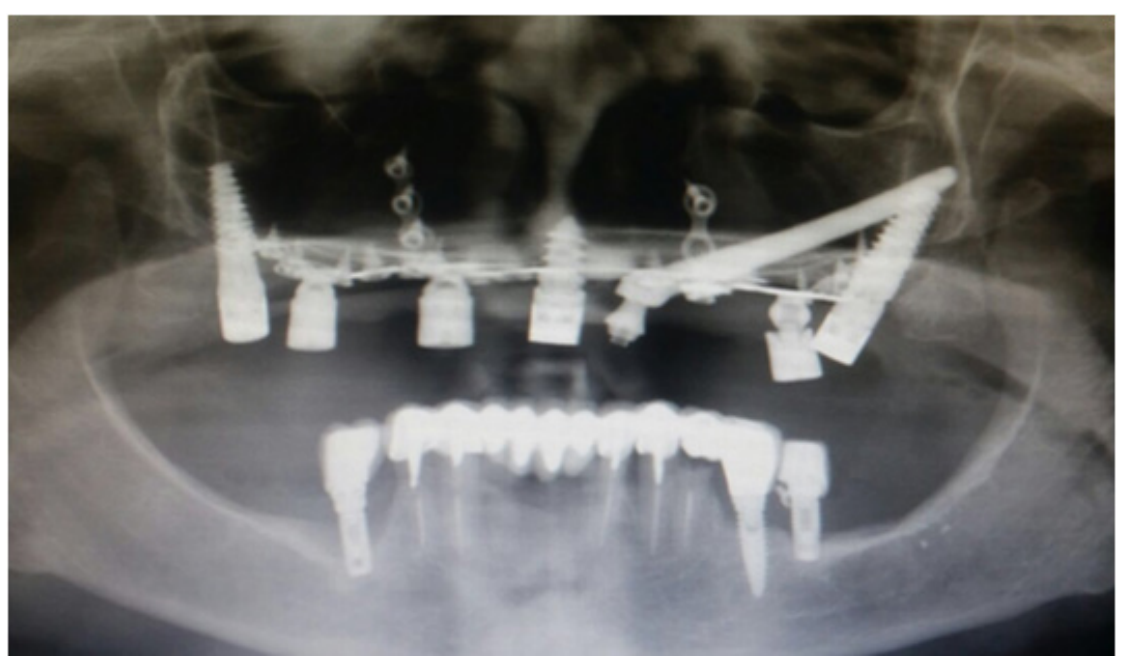

Figure 3: CF@O implant system and screws: a) Pterygoid implant, b) hybrid Plates, c) Compressive implant and D) Osteosynthesis Screws.

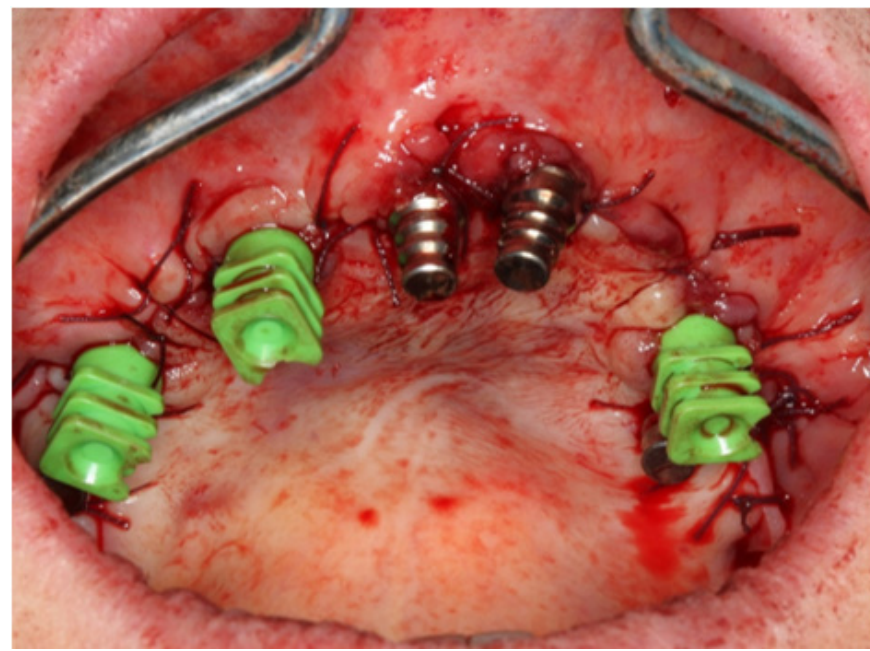

Figure 4: Preparation for impression taken.
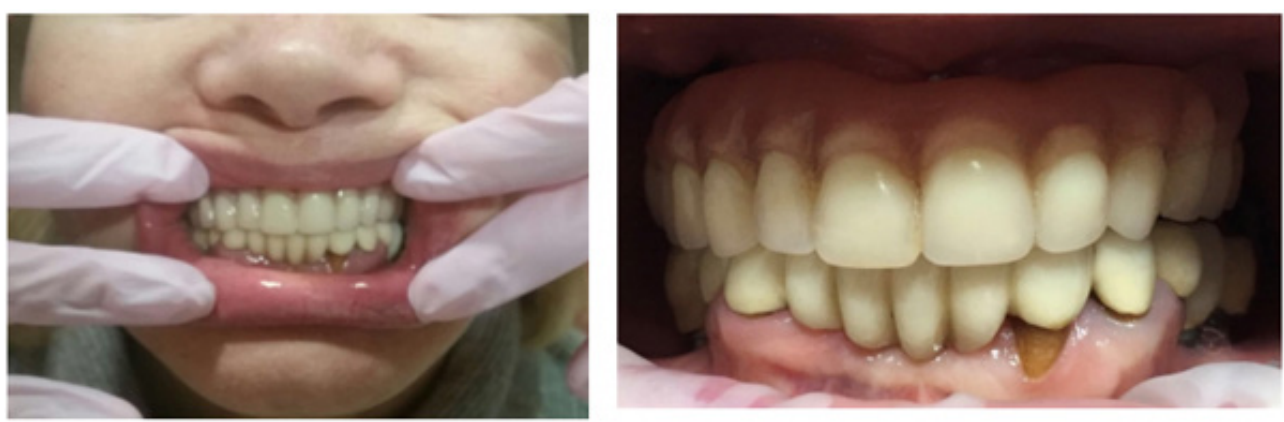

Figure 5: The clinical picture of the patient at the completion of the treatment.

\section{Discussion}

The presented case reports describe the clinical steps followed for the retreatment and functional restoration of occlusion in a patient with failed implants with the CF@O implant system.CF@0 incorporates the whole range of treatment procedures available to the implantologist, and it is a reliable alternative where there is substantial bone resorption. Rehabilitation of difficult and failed implant cases is achieved within a short period of time without the need for extensive surgical operation. Early loading ensures that patient edentulism can be taken care of immediately. In the above case reports, CF@0 hybrid plate and pterygoid implants were used for patient rehabilitation. The use of hybrid plates and pterygoid implants to support a fixed bar was demonstrated to be a reliable, predictable alternative to distal cantilever prostheses or 
sinus-lifting procedures. This technique has good success rate and it ensures short treatment period.

\section{References}

1. Ali SA, Karthigeyan S, Deivanai M, Kumar A (2014) Implant rehabilitation for atrophic maxilla: A review. J Indian Prosthodont Soc 14(3): 196-207.

2. Att W, Bernhart J, Strub JR (2009) Fixed rehabilitation of the edentulous maxilla: Possibilities and clinical outcome. J Oral Maxillofac Surg 67(11): 60-73.

3. Fernandez H, Gomez-Delgado A, Trujillo-Saldarriaga S, Varon-Cardona D, Castro-Nunez J (2014) Zygomatic implants for the management of the severely atrophied maxilla: A retrospective analysis of 244 implants. J Oral Maxillofac Surg 72(5): 887-891.

4. Yates JM, Brook IM, Patel RR, Wragg PF, Atkins SA, et al. (2014) Treatment of the edentulous atrophic maxilla using zygomatic implants: Evaluation of survival rates over 5-10 years. Int J Oral Maxillofac Surg 43(2): 237242.

5. Mericske-Stern RD, Taylor TD, Belser U (2000) Management of the edentulous patient. Clin Oral Implants Res 11(1): 108-125.

\section{ISSN: 2574-1241}

DOI: 10.26717/BJSTR.2018.06.001427

Henri Diederich. Biomed J Sci \& Tech Res

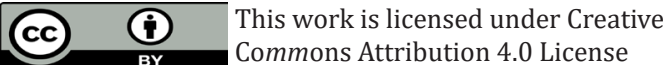

Submission Link: https://biomedres.us/submit-manuscript.php
6. Sjostrom M, Sennerby L, Nilson H, Lundgren S (2007) Reconstruction of the atrophic edentulous maxilla with free iliac crest grafts and implants: A 3-year report of a prospective clinical study. Clin Implant Dent Relat Res 9(1): 46-59.

7. Ugurlu F, Yildiz C, Sener BC, Sertgoz A (2013) Rehabilitation of posterior maxilla with zygomatic and dental implant after tumor resection: a case report. Case Rep Dent 2013: 930345.

8. Yaremchuk MJ (1989) Vascularized bone grafts for maxillofacial reconstruction. Clin Plast Surg 16(1): 29-39.

9. Bidra AS, Huynh-Ba G (2011) Implants in the pterygoid region: a systematic review of the literature. Int J Oral Maxillofac Surg 40(8): 773781.

10. Bosse LP, Taylor TD (1998) Problems associated with implant rehabilitation of the edentulous maxilla. Dent Clin North Am 42(1): 117127.

11. Nystrom E, Nilson H, Gunne J, Lundgren S (2009) Reconstruction of the atrophic maxilla with interpositional bone grafting/Le Fort I osteotomy and endosteal implants: A 11-16year follow-up. Int J Oral Maxillofac Surg 38(1): 1-6.

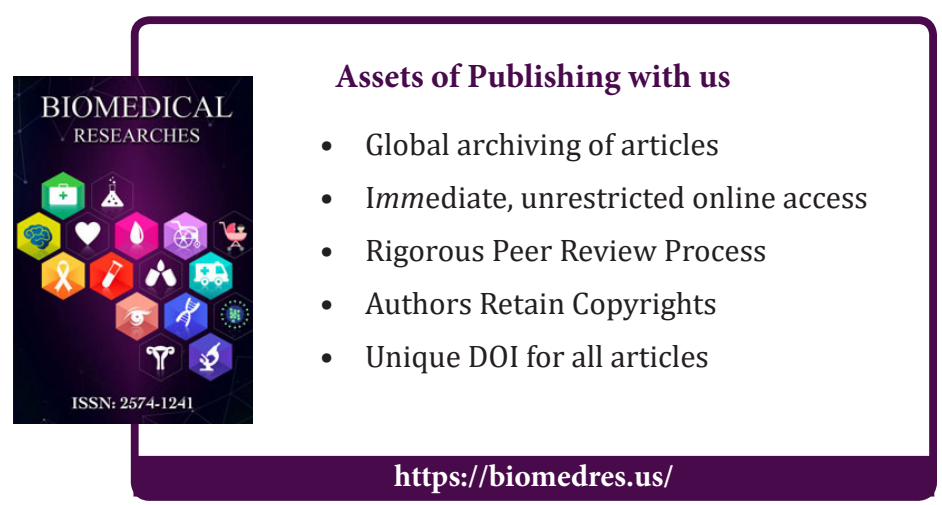

